\title{
Analysis of the requirements of the wire rod production standards in Ukraine
}

\author{
Yershov Serhiy, D. ${ }^{1}$, Samokhval Volodymyr ${ }^{2}$, \\ Antonov Yuri ${ }^{3}$, Medinsky Gregory ${ }^{4}$
}

${ }^{1}$ Eng. Science, professor Dneprodzerzhinsk State Technical University, Dneprodzerzhinsk, Dneprobudivskaya street, 2, Ukraine, 51900,

${ }^{2}$ Ph.D. in Technical Science, Dneprodzerzhinsk, Dneprobudivskaya street 2, Ukraine, 51900,

${ }^{3}$ Eng., Technical Head of Dneprovsky integrated Iron and Steel Works, Dneprodzerzhinsk, Kirova street, 18, Ukraine, 51900,

${ }^{4}$ Eng., Head of rolling laboratory of Dneprovsky integrated Iron and Steel Works, Dneprodzerzhinsk, Kirova street, 18, Ukraine, 51900,

${ }^{1}$ s.ershov@mail.ru*, ${ }^{2}$ volsamokhval@gmail.com,

${ }^{3}$ dir-antonov@dmkd.dp.ua, ${ }^{4}$ cltu-medinsky@dmkd.dp.ua

Keywords: standards, specifications, wire rod, dimensions, tolerances, roundness

\begin{abstract}
It is observed the dynamic of changes in the requirements of national and international standards for production of wire rod. It is shown that the general trend in changing of requirements is not a tightening of technical parameters but in some cases the extension of the range of variation of parameters, which provides the wide opportunities for producers.
\end{abstract}

\section{Introduction}

Wire rod has always been and remains the most popular type of rolled product. Due to a variety of applications of products from wire rod - from the soft clips to the high strength ropes, the wire rod that manufactured at rolling mills has a wide range of sizes, steel grades and mechanical properties. In most cases, this semifinished product is rolling as product that primarily intended for further processing.

Consumers of wire rod, trying to improve the efficiency of their manufacturing processes, constantly increase the requirements for this type of raw material. Takin into account the increasing demands of consumers, the producers of wire rod have to constantly improve the equipment and process technology to ensure the competitiveness of their products. Most clearly this trend is seen in the accuracy of rod sizes. Leading manufacturers of wire rod declare the possibility of its manufacturing processes to make the product with tolerances that less than $\pm 0.1 \mathrm{~mm}$. For example, the Danieli Company [1] offers a high-speed technology for manufacturing wire rod with a diameter of 4.5 to $25 \mathrm{~mm}$ in coils with weight up to 3.5 tones, tolerances $\pm 0.075 \mathrm{~mm}$ and a roundness up to $50 \%$ of the summary tolerance field.

For achievement such level of accuracy in addition to usual finishing blocks of stands with cantilevered rolls, the producers have to use a different innovative technical solutions. For example, the reduction-calibrating blocs of two - four stands with cantilevered rollers [2], calibration blocks of three-roll or four-roll stands [3], stand of cassette-type [4], the automatic control system [5].

\section{Problem formulation}

In this case, we have a question. How is justified such a significant investment in the development of equipment, technologies, their implementation and how is reflected this situation in the current standards?

The purpose of this paper is to analyze the trends of the requirements of national and international standards to the most popular type of rolled products - wire rod. 


\section{The results of work}

"Steel wire rod is called a profile with circular cross-section with diameter 5 - $9 \mathrm{~mm}$ that producing on the wire rolling mills and undergoes by coiling".

In accordance to GOST 2590-57 (Interstate Standard of CIS countries with number - 2590 and year of issue - 1957) the base tolerance of diameter of rod is $\pm 0,5 \mathrm{~mm}[6, \mathrm{p} .220]$. However, the standard GOST 2590-57 "Hot-rolled round steel" provides additional two levels of precision of the wire rod: common tolerance with ultimate deviations of dimensions from +0.3 to $0.5 \mathrm{~mm}$ and higher tolerance - from +0.1 to $-0.3 \mathrm{~mm}$ (Fig. 1). The tolerance in range of $\pm 0.5 \mathrm{~mm}$ is shown in the notes as "allowable". Such features of standard requirements clearly illustrate the tendency of standards to improve the accuracy of rolling production, but "allowing" production of wire with quality that can be achieved in some metallurgical plants with old equipment.

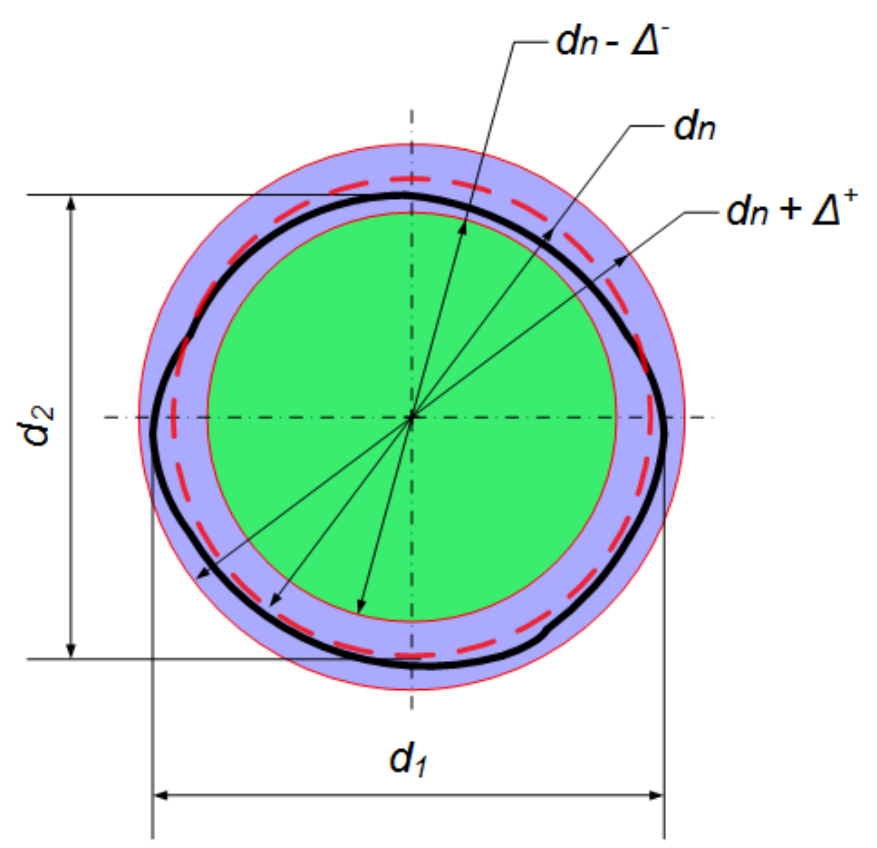

$d_{n}$ - nominal diameter of the wire rod;

$\Delta^{-}$- minus deviation of the nominal diameter;

$\Delta^{+}$- plus deviation of the nominal diameter;

$\left(\Delta^{-}+\Delta^{+}\right)$- field of tolerance - the sum of deviations;

$\left(d_{n}-\Delta^{-}\right)$- minimal allowable diameter;

$\left(d_{n}+\Delta^{+}\right)$- maximal allowable diameter;

$d_{1}, d_{2}$ - real dimension of wire rods;

$\left|d_{1}-d_{2}\right|$ - roundness.

Figure 1 - Possible and actual rod dimensions

Standard that was issued in 1957 provided the diameters of wire rod: $5.0 ; 5.6 ; 6.0 ; 6.3 ; 6.5$; $7.0 ; 8.0 ; 9.0 \mathrm{~mm}$. This standard was revised in 1971 and 1988.

Since the 1971-year edition, the sizes of wire rod was remained unchanged, but it was provided three classes of accuracy: A - high; B - increased; V - the common. The tolerances that respectively specified accuracy classes are as follows: $+0.1 \ldots-0.2 \mathrm{~mm} ;+0.1 \ldots-0.5 \mathrm{~mm} ;+0.3 \ldots-$ $0.5 \mathrm{~mm}$. We need to note that the tolerances for the common accuracy of wire rod was remain unchanged and for increased accuracy it was increased an ultimate negative range of tolerance. We can see that additional class of precision (class A) reflects the technical ability to manufacture the products with higher level of technical demands in new rolling mills. However, in the notes to standard was saved term "allowed" that allow dimensions deviations in range of $\pm 0.5 \mathrm{~mm}$ with a limited validity period up to 01.01.1992. Thus, the requirements of GOST 2590-88 reflect increased technical capabilities of the rolling equipment for improving of accuracy of wire rod, but it "allow" production of wire rod with low accuracy during limited-time period.

The next edition of the same standard was adopted in 2006. In Ukraine this standard has obtained a status of a national standard and it was labeled DSTU 4738: 2007 / GOST 2590-2006 [7].

This designation of standard shows that it is the State Standard of Ukraine (DSTU) with the number of 4738 in the edition of 2007 year. This standard is applicable in the territory of Ukraine. The requirements of this standard are identical to the requirements of the interstate standard GOST 2590-2006. This standard is applicable not only in the territory of Ukraine but it is applicable in the 
territory of the CIS countries. At the same time, both of these standards has been developed on the base of requirements of the European standard EN 10060: 2003. However, standard GOST 25902006 is not identical to European standard and has some differences. A more detailed ratio of requirements of national (DSTU) and international standards (GOST, EN) are described in the introduction to the national standard DSTU 4738: 2007, the full text of which is available on a different information resources, for example on the site http://www.leonorm.com.

If we look to standard DSTU 4738:2007 in more detail we have seen that it provides already not three groups of precision as earlier but four groups of precision for round profiles, with the partitioning some of them into sub-groups:

- particularly high - A01;

- high A1, A2, A3;

- increased B1;

- common V1, V2, V3, V4, V5.

The tolerances of diameters for all of the rod sizes depends on the accuracy of the group and set in the following range:

AO1 - as agreed with the customer;

$\mathrm{A} 1:+0.1 /-0.2 \mathrm{~mm} ; \mathrm{A} 2: \pm 0.15 \mathrm{~mm} ; \mathrm{A} 3:+0.3 \mathrm{~mm}$;

$\mathrm{B} 1:+0.1 /-0.5 \mathrm{~mm}$;

$\mathrm{V} 1:+0.3$ / $-0.5 \mathrm{~mm} ; \mathrm{V} 2: \pm 0.4 \mathrm{~mm}$; V3: $+0.8 \mathrm{~mm}$; V4: $+0.5 \mathrm{~mm}$; V5: $\pm 0.5 \mathrm{~mm}$

The analysis of these values shows that the pre-existing three levels of precision, that was regulated by the previous version of the standard, was saved and was added the group "very high precision" with tolerance less than $0.3 \mathrm{~mm}$. Showed partitioning into groups allows manufacturers more flexibility characterize their products. For example, the rolled wire rods can be produced with precision group A (tolerance $0.3 \mathrm{~mm}$ ). But subgroup A1 has nonsymmetrical deviation within range of $+0.1 /-0.2 \mathrm{~mm}$, subgroup A2 has symmetrical deviation $\pm 0.15 \mathrm{~mm}$, subgroup A3 has only positive deviation $+0.3 \mathrm{~mm}$.

Our attention is captured to the note: "For profiles with diameter $9 \mathrm{~mm}$ or less, that are manufactured in coils at rolling mills and which are not equipped with finishing-blocks of stands are allowed to have tolerances of diameter that are not more than $\pm 0,5 \mathrm{~mm}$ (accuracy subgroup V5)" [7]. We have seen that we have repeated situation as in the standard that was published in 1957. It make possible to manufacture the rods with tolerance in range of $1 \mathrm{~mm}$. Consequently, the current new standards are not tightened requirements and support the ability to produce products in existing equipment, but provide greater gradation levels of accuracy to improve the competitiveness of products.

This conclusion is confirmed by the changes in the requirements for roundness of wire rod. If in the 1988 year standard edition the requirements to roundness are formulated as "... shall not exceed $50 \%$ of the tolerances on diameter", the new version of standard (2006 year) requires that "... shall not exceed $75 \%$ of the tolerances on diameter". However, on consumer demand the ovality of round profile may be set at "no more than $50 \%$ of the maximum deviations of the diameter."

The diameter and roundness of rolled product measuring at a distance that is not less than $100 \mathrm{~mm}$ from the end of the profile and not less than $1.5 \mathrm{~m}$ from the end of the coil with its weight up to $250 \mathrm{~kg}$. If the weight of the coil exceeds $250 \mathrm{~kg}$ the measuring is conducted at a minimum distance of $3.0 \mathrm{~m}$ from the end of the profile.

As was noted earlier, the investigated standard is based on the following standards: GOST 2590: 2006 and EN 10060:2003. At the same time, the European standard regulates the requirements for hot-rolled bars (Hot rolled round steel bars for general purposes. Dimensions and tolerances on shape and dimensions). For the common wire rods this standard contains a reference to European standard EN 10017:2004 (Steel rod for drawing and / or cold rolling. Dimensions and tolerances). In accordance to demands of standard EN 10017:2004 the wire rods with a diameter from 5 to $9.5 \mathrm{~mm}$ should have the ultimate deviation of diameter not more than $\pm 0,3 \mathrm{~mm}$ and the roundness up to $80 \%$ of the summary tolerance $(0.48 \mathrm{~mm})$. 
In addition to the assortment standard for product DSTU 4738: 2007 and GOST 2590-2006 the technical requirements for wire rod in dependence on it application have defined by following standards:

DSTU 2770-94 (GOST 30136-95, ISO 8457/1-89) [8];

DSTU 3683-98 [9];

DSTU ISO 16120-1:2009 [10];

The first two standards contain references to GOST 2590-88. In this case, the accuracy of the rod is determined by the assortment standard, which has been canceled. Obviously, the manufacturers of wire rod is guided by the requirements of the assortment standard in version of 2006 year.

According to the standard DSTU ISO 16120-1:2009, that was started to use in 2011, the term wire rod was formulated as "rolled round, oval, square, rectangular, hexagonal, semicircular profile or a different profile, that are have usually a nominal size of $5 \mathrm{~mm}$ with a smooth surface "[10]. The first part of this standard specifies the general requirements for non-alloy steel wire rod that was made for further treatment and obtaining the wire and does not apply to products intended for further heat treatment, pressing or producing the wire rod for special applications. Standards of series of ISO 16120 sets new product designations, with taking into account the steels that corresponding to standards ISO 4948-1 and ISO 4948-2. For example, a rod with diameter of 5.5 $\mathrm{mm}$, the common accuracy class T1 with carbon content up to $0.09 \%$ and ultimate strength of 800 $\mathrm{MPa}$ is labeled as:

$200 \mathrm{t}$ round wire rod ISO $16124-5.5 \mathrm{~T} 1$

ISO 16120-1 - C9D2-800

ISO 10474 S9D2-800 the act of acceptance control 3.1.V.

From the data have showed above we have seen that the size and the level of precision of wire rod products are governed by an international standard, which was named in Ukraine as DSTU ISO 16124:2009 [11]. In accordance to the requirements of this standard for round product are provided the dimensional row with diameters from 5 to $50 \mathrm{~mm}$ with interval of $0.5 \mathrm{~mm}$ up to diameter of $20 \mathrm{~mm}$ and after that with interval of $1 \mathrm{~mm}$. There are three classes of accuracy: common T1; increased T2; high T3. For a rod with a diameter from 5 to $10 \mathrm{~mm}$ the diameter tolerances are:

$$
\mathrm{T} 1- \pm 0.3 \mathrm{~mm} ; \mathrm{T} 2- \pm 0,25 \mathrm{~mm} ; \mathrm{T} 3- \pm 0.15 \mathrm{~mm} \text {. }
$$

The level of accuracy T3 corresponds to level of high precision A2 in standard DSTU 4738:2007 / GOST 2590-2006, and the level of common accuracy T1 corresponds to level higher precision $\mathrm{B} 1$ (with tolerance of $0.6 \mathrm{~mm}$ ). Note that the standards that have issued with a difference in three years, the level of precision for common class has changed from $0.8 \mathrm{~mm}$ to 0.6 $\mathrm{mm}$, and the level of precision for higher tolerance has not changed (Fig. 2). At the same time, the State Standard DSTU ISO 16124:2009 does not provide a possibility for manufacture the wire rod with tolerance of $1.0 \mathrm{~mm}$.

The valid values of wire rod roundness with a diameter up to $10 \mathrm{~mm}$ in dependence on the accuracy class are:

T1 - up to $0.48 \mathrm{~mm}$; T2 - up to $0.40 \mathrm{~mm}$; T3 - up to $0.24 \mathrm{~mm}$.

It is show that roundness of product must not exceed $80 \%$ of the summary tolerance.

Comparison of the requirements of the standards DSTU 4738:2007 / 2590-2006 and DSTU ISO 16124:2009 shows that their requirements to the accuracy of rolled product are sufficiently close. In any case, these requirements do not contradict to each other. Changes in product requirements to a greater level are not associated with the revision of standards but with a total unification caused by the transition to the use of international standards and changes in the classification of steels. At the same time, the newly introduced national standards, based on international standards, do not provide increasing of requirements, but reflect a general tendency to increase the accuracy of rolling production with using of modern equipment. For such a measure as the roundness, we have even extension of allowed values. 
If we restrict ourselves in analysis with the maximum and minimum fields of diameter tolerances for the wire rod, we can see that since 1957 the standards are changed insignificantly. The maximum field of tolerance has not changed and remain $0.8 \mathrm{~mm}$. At the same time, the standard DSTU 4738:2007 / 2590-2006 is applicable in the present time. In addition to this standard now is applicable the standard DSTU ISO 16424:2009 since 2011. In accordance to that standard, the maximum field of tolerances has reduced to $0.6 \mathrm{~mm}$. In accordance to both existing standards for high precision wire rod, the minimal field of tolerances $(0.3 \mathrm{~mm})$ was not changed since 1971 year

(Fig. 3).

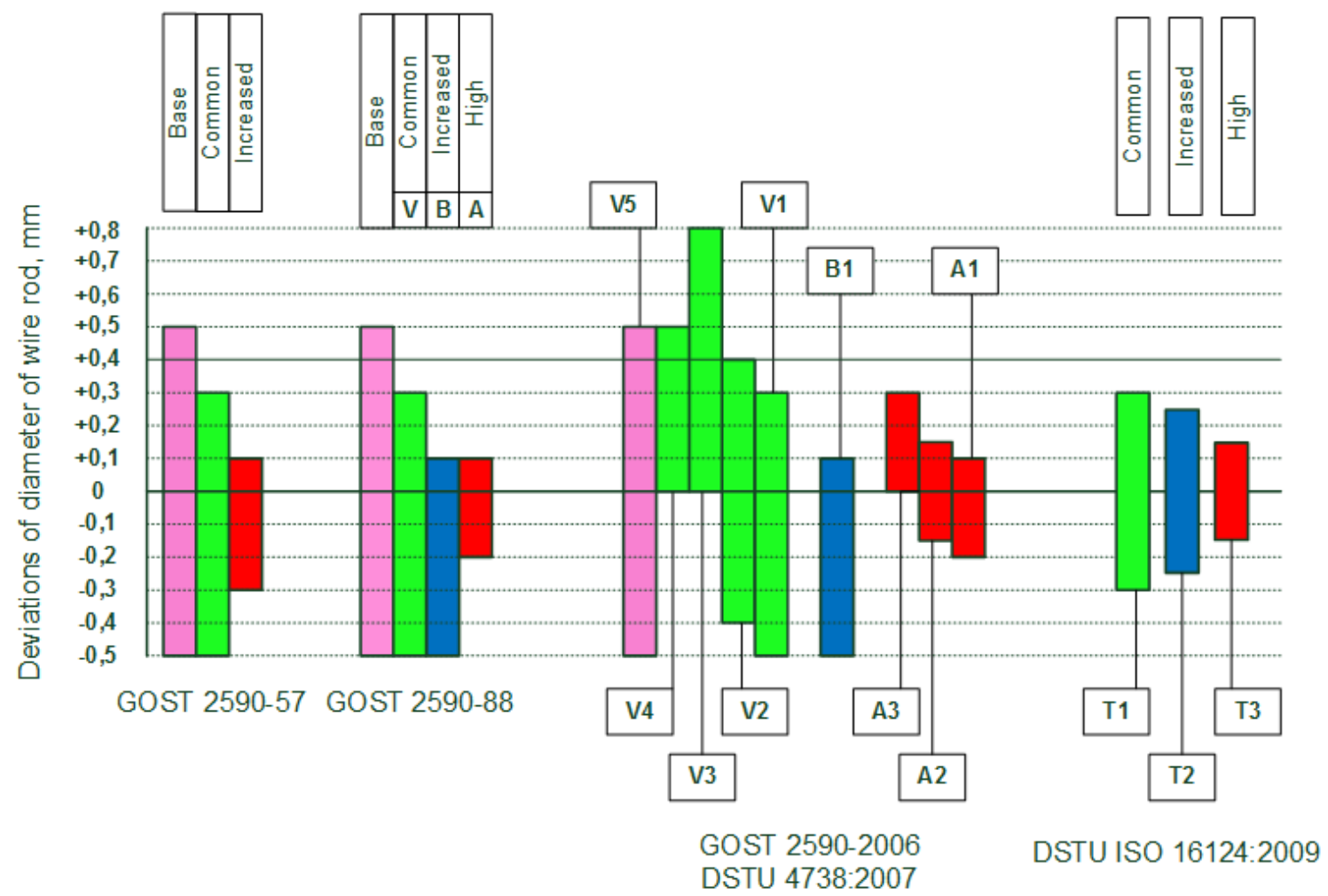

Figure 2 - Graphical representation of diameter tolerances for rods in according to the requirements of different standards

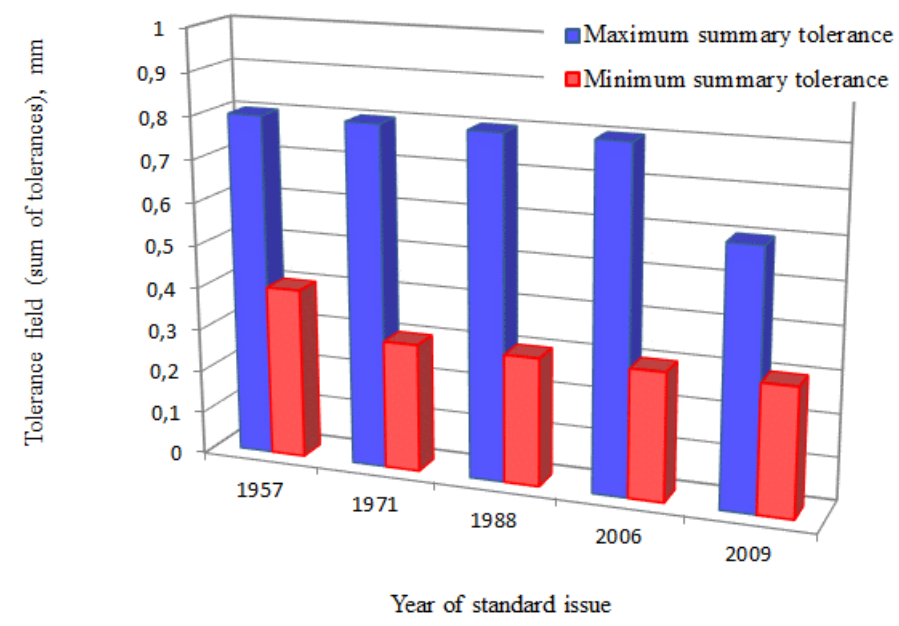

Figure 3 - Dynamics of changes in the minimum and maximum fields of rod tolerances 
Standard DSTU ISO 16120-1:2009 regulates the chemical composition of steel (carbon, silicon, manganese, phosphorus, sulfur, chromium, nickel, molybdenum, copper, aluminum); the tensile strength, the amount of decarbonized layer, the score of center segregation and microstructure. There are steels with a carbon level from less than $0.06 \%$ to $0.95 \%$. The carbon level of steel is reflected in its designation. For example, the above mentioned designation C9D2800 mean that the carbon level up to $0.1 \%$, the steel is intended for further drawing, a tensile strength of at least $800 \mathrm{MPa}$.

The wire that manufacturing for export in metallurgical plants of Ukraine in most cases is made in accordance with US standard ASTM A510. This standard was issued in 2006 (ASTM A510m - 2006) and covers the general requirements for carbon steel wire rods and uncoated rough round wire in coils or round wire that was straightened and was cut to certain lengths. The standard provides an accurate definition of rod [12]:

"Wire rods - rods that are hot rolled from billets to an approximately round cross section and into coils of one continuous length. Rods are not comparable to hot-rolled bars in accuracy of cross section or surface finish and as a semi-finished product are intended primarily for the manufacture of wire"

Dimensions of wire rod, in accordance to the standard A510, set to the following [12]:

$5.5 ; 6.0 ; 6.5 ; 7.0 ; 7.5 ; 8.0 ; 8.5 ; 9.0$ and further through each $0.5 \mathrm{~mm}$ up to diameter of $19 \mathrm{~mm}$.

The ultimate deviation of diameter for the entire range of profiles are set identical: $\pm 0,4 \mathrm{~mm}$. The roundness must not exceed $0.635 \mathrm{~mm}$.

The standard specifies the chemical composition of the steel for the production of wire rod. Under regulation are carbon, manganese, phosphorus, sulfur, silicon, copper and lead. It is provided a sufficiently large number of steels with a carbon content from $0.06 \%$ (SAE 1005) to $1.03 \%$ (SAE 1095). The chemical composition of steel for the manufacture of round bars is partitioned into groups in dependence on the level of sulfur (without removing the sulfur, without removing the sulfur but with presence of manganese, steels with partly removed sulfur), as well as the sulfur and the phosphorus simultaneously (steels with partly removed phosphorus steels with partly removed sulfur).

Metallurgical structure involves determining the grain size, if such standardized, and absence of the not tempered martensite.

The mechanical properties must be determined in accordance with the regulations "Test Methods and Definitions" A370.

In accordance with Japanese standards: JIS G3502, JIS G3505, JIS G3506, JIS G3507-1 wire rods are manufactured with the following diameters (in $\mathrm{mm}$ ): $5.5 ; 6.0 ; 6.5 ; 7 ; 8 ; 9 ; 10$ and further up to $20 \mathrm{~mm}$ [13]. To the row of wire rod in Japan were included profiles with diameter from 4.2 to 19 $\mathrm{mm}$. A long steel in coils is supplied with a diameter up to $52 \mathrm{~mm}$. Standard JIS G3505:2004 (Low carbon steel wire rods) is not provided partitioning into groups of accuracy. It is regulated only tolerance (range of tolerance) at the rate of $6-9 \%$ of the nominal diameter. For wire rod, as the diameter is increasing, set the symmetrically tolerances $\pm 0.25 ; \pm 0,3 ; \pm 0.4 \mathrm{~mm}$. However, manufacturers declare the possibility of producing the rods with tolerances $\pm 0.1 \mathrm{~mm}$, minimum diameter of $4.2 \mathrm{~mm}$ and a size gradation through each $0.1 \mathrm{~mm}[14,15]$. They say the roundness of wire rod is less than half of the sum of tolerances.

As can be seen from a comparison of the requirements of national standards of Ukraine, US and Japan to the wire rod that shown in Fig. 4, the technical possibilities of modern rolling mills allow to produce wire rod with deviation of sizes up to half of tolerance for high precision wire rod that prescribed in standards.

Thus, the standards of foreign countries (Table 1) provides a wide enough range of changes in the values of technical parameters, but the producers introduce its own standards that provide a substantial excess of requirements of existing standards to ensure the competitiveness of its products. 
For example, manufacturers of rods in Japan declare possibility of delivery of rods with diameters gradation through each $0.1 \mathrm{~mm}$, whereas the standard declare it value in range of 0.5 or $1.0 \mathrm{~mm}$.
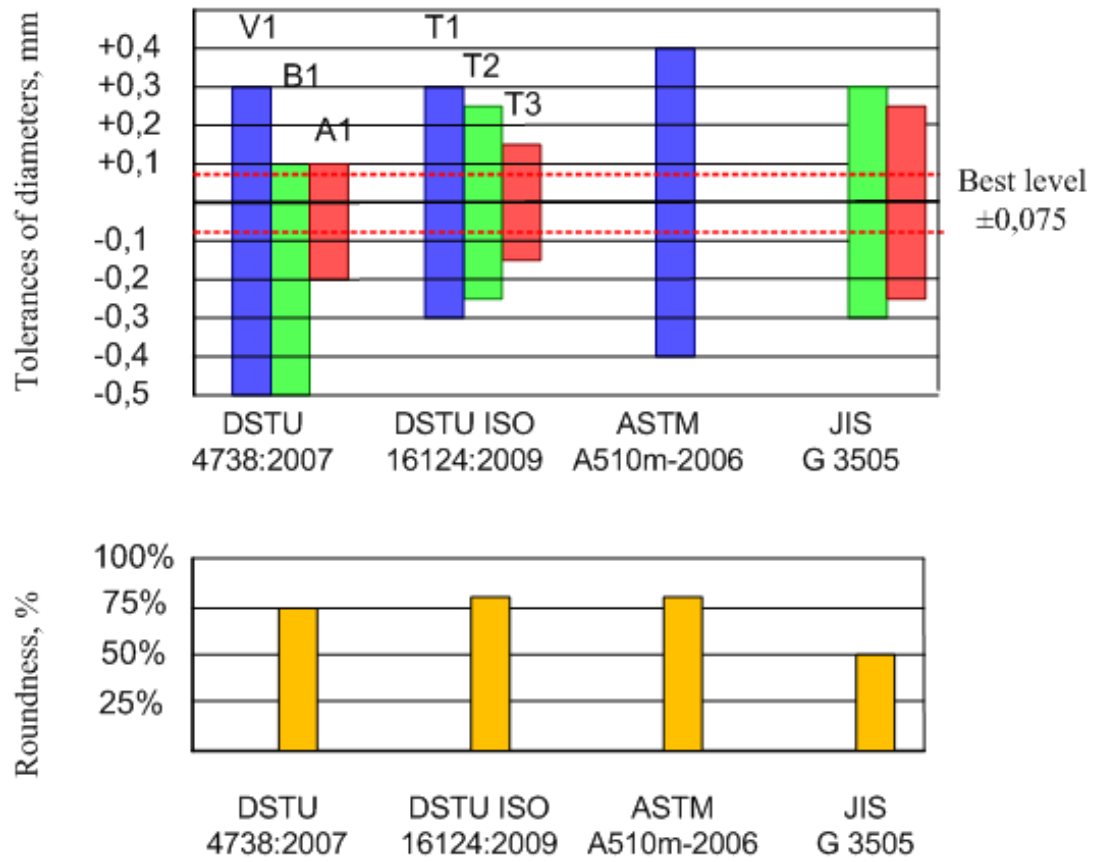

Figure 4 - Comparison of requirements of the standards for the accuracy of rod sizes:

Ukraine, United States and Japan

Table 1 - The comparison of the requirements of standards

\begin{tabular}{|c|c|c|c|c|c|}
\hline \multirow{2}{*}{$\begin{array}{l}\text { Controllable } \\
\text { parameter of } \\
\text { wire rods }\end{array}$} & \multicolumn{5}{|c|}{$\begin{array}{l}\text { Options, rod values, classes, groups or the range of variation of parameters } \\
\text { in accordance with standards }\end{array}$} \\
\hline & $\begin{array}{c}\text { DSTU } \\
\text { 4738: } 2007 \text {, } \\
\text { Ukraine }\end{array}$ & $\begin{array}{c}\text { EN 10017: } \\
2004, \\
\text { EU }\end{array}$ & $\begin{array}{c}\text { DSTU ISO } \\
\text { 16124: } 2009 \\
\text { Ukraine }\end{array}$ & $\begin{array}{c}\text { ASTM A } \\
510 M-2006 \\
\text { US }\end{array}$ & $\begin{array}{c}\text { JIS G } 3505, \\
\text { Japan }\end{array}$ \\
\hline $\begin{array}{c}\text { Range of } \\
\text { diameters, }[\mathrm{mm}]\end{array}$ & $\begin{array}{c}5,0 ; 5,5 ; 6,0 \\
6,3 ; 6,5 ; 7,0 \\
8,0 ; 9,0 ; 10\end{array}$ & & $\begin{array}{c}5,0 ; 5,5 ; 6,0 ; 6,5 \\
7,0 ; 7,5 ; 8,0 ; 8,5 \\
\quad 9,0 ; 9,5 ; 10\end{array}$ & $\begin{array}{l}5,5 ; 6,0 ; 6,5 ; \\
7,0 ; 7,5 ; 8,0 ; \\
8,5 ; 9,0 \text { and } \\
\text { further to } 19\end{array}$ & $\begin{array}{l}5,5 ; 6,0 ; 6,5 ; 7 ; 8 ; \\
9 ; 10 \text { and further } \\
\text { through } 1 \mathrm{~mm} \text { до } \\
20 \mathrm{~mm}\end{array}$ \\
\hline $\begin{array}{c}\text { Tolerances of } \\
\text { diameters, }[\mathrm{mm}]\end{array}$ & $\begin{array}{c}\text { A01; } \\
\text { A1 }(+0,1 /-0,2) ; \\
\text { A2 }( \pm 0,15) ; \\
\text { A3 }(+0,3) ; \\
\text { B1 }(+0,1 /-0,5) ; \\
\text { B1 }(+0,3 /-0,5) ; \\
\text { B2 }( \pm 0,4) ; \\
\text { B3 }(+0,8) ; \\
\text { B4 }(+0,5) ; \\
\text { B5 }( \pm 0,5) ;\end{array}$ & $\pm 0,3$ & $\begin{array}{c}\text { T1 - } \pm 0,3 ; \\
\text { T2 - } \pm 0,25 ; \\
\text { T3 - } \pm 0,15 .\end{array}$ & $\pm 0,4$ & $\begin{array}{cc}5,5-7,0 & \pm 0,25 \\
8-10 & \pm 0,30 \\
11-20 & \pm 0,40\end{array}$ \\
\hline $\begin{array}{l}\text { Roundness, } \\
{[\mathrm{mm}]}\end{array}$ & $\begin{array}{l}75 \% \text { of the } \\
\text { tolerance }\end{array}$ & $\begin{array}{l}80 \% \text { of the } \\
\text { tolerance } \\
(0,48 \mathrm{~mm})\end{array}$ & $\begin{array}{c}\text { T1 - to } 0,48 \\
(80 \%) ; \\
\text { T2 - to } 0,40 \\
(80 \%) ; \\
\text { T3 - to } 0,24 \\
(80 \%) .\end{array}$ & $\begin{array}{l}\leq 0,6 \\
(75 \%)\end{array}$ & $\begin{array}{c}5,5-7,0<0,25 \\
(50 \%) ; \\
8-10<0,30 \\
(50 \%) ; \\
11-20<0,40 \\
(50 \%)\end{array}$ \\
\hline
\end{tabular}




\section{Conclusions}

1. The increased capabilities of modern technology and equipment to improve the accuracy is reflected in the standards for wire rod in the form of reduced tolerances, large groups of graduation accuracy and exception of values that are typical for older mills.

2. The newly introduced national standards do not provide strengthening of requirements in all cases. In most cases, it provides a very wide range of technical parameters, or even the extension of allowable values in some cases. For example in the range of roundness.

3. A characteristic feature of standardization in the metallurgical industry is the move to standards that are based on international, mainly to European (Euro norms) or to the standards of International Organization for Standardization (ISO). At the same time, the main innovations in standards are result of changes in the classification and designation of steels.

4. For the newly introduced product standards, mainly for foreign standards, it is usually use the symmetrical tolerance range of size deviation.

5. The standards of the foreign countries provide a quite wide range of ultimate level of parameters that considerably wider than the technical capabilities of existing technologies. However, the producers introduce its own standards that provide a substantial excess of requirements of existing standards to ensure the competitiveness of its products.

6. In our opinion, it is required modification of the existing standards, which will reflect the actual consumer demands for precision of rolled profiles. This requires the addition of the new class of accuracy for products with more strong requirements for the profile geometry.

\section{References}

[1] H3 - Wire Rod Mills, Bar-in-coil, Long products, Daniely, Relies 310, Information on http://www.danieli.com.

[2] Morgan Rod Reducing and Sizing Mill. Setting the standard in rod rolling for unsurpassed productivity, tolerances and mechanical properties, Siemens-VAI, 2013, Information on www.industry.usa.siemens.com.

[3] T. Sakurai, T. Sakamoto, R. Takeda, Development of high dimensional accuracy smaller diameter wire rods and square coils manufactured by 4-Roll, Kawasaki steel technical report, N. 47 (2002) $42-47$.

[4] M. Zuccato, M. Tomba, A. Fontanini, N. Tomba, Second generation of Bi-Support rolling stands, Metallurgical Plant and Technology International, Vol. 36, N.1 (2013) 48 - 50.

[5] Y. Noguchi, H. Ogai, K. Okamura, Characteristics of continuous wire rod rolling and precision rolling, Nippon steel technical report, N. 80 (1999) $79-83$.

[6] A. P. Chekmariov, M. S. Mutiev, R. A. Mashkovtcev, Roll design, Metallurgy, Moscow, 1971.

[7] DSTU 4738:2007, GOST 2590-2006, Profiles round of hot-rolled steel, Assortment, Derzhspozhivstandart, Kyiv, 2008.

[8] DSTU 2770-94, GOST 30136-95, ISO 8457/1-89, Rolled carbon steel of usual quality, Technical conditions, Derzhspozhivstandart, Kyiv, 1996.

[9] DSTU 3683-98, Rolled steel cable, Specifications Derzhspozhivstandart, Kyiv, 1998.

[10]DSTU ISO 16120-1:2009, Non-alloy steel wire rod for conversion into wire, Part 1, General Derzhspozhivstandart, Kyiv, 2011.

[11]DSTU ISO 16124:2009, Wire rod steel, Dimensions and tolerances Derzhspozhivstandart, Kyiv, 2011.

[12] ASTM A510M-06, Standard Specification for General Requirements for Wire Rods and Coarse Round Wire, Carbon Steel, and Alloy Steel, 2006 
[13] JIS G 3505:2004, Low carbon steel wire rods, STANDARD by Japanese Industrial Standard, Japanese Standards Association, 2004.

[14]R. Seki, K. Hasegawa, K. Nakajima, K. Yoshimura, Making to high performance and productivity improvement of steel bar and wire rod rolling process, Nippon steel technical report, N. 96 (2007) $21-28$.

[15] Steel bars and wire rods from JFE, JFE Steel Corporation, Information on http://www.jfesteel.co.jp. 